\title{
Comparative study of diagnostic value of Apo lipoprotein AI in neonatal sepsis in Relation to hematological score \\ I.A.Ramadan $^{1}$, E.R.Abdel Gwad ${ }^{2}$, E.H.Assar ${ }^{1}$, T.G.Ali ${ }^{1}$ \\ ${ }^{1}$ pediatrics, Dept., Faculty of Medicine, Benha Univ., Benha, Egypt \\ ${ }^{2}$ Clinical and Chemical Pathology, Dept., Faculty of Medicine, Benha Univ., Benha, Egypt \\ E-mail:Taghreed.elsaer89@gmail.com
}

\begin{abstract}
Objective The aim of this study is to study serum level of Apolipoprotein A1 as a diagnostic marker in neonatal sepsis in relation to haematological score. Background: Neonatal sepsis has become a global health problem due to its high morbidity and mortality. Blood culture continues to be the main method to diagnose neonatal sepsis. The present work aimed to study of serum level of Apolipoprotein A1 as a diagnostic marker in neonatal sepsis in Relation to Hematological score. Methods: This study is a case control study, which was done on 60 neonates who admitted to neonatal ICU (NICU) of Benha University Hospitals and Benha Teaching Hospitals of both sexes after obtaining an informed consent from the children's caregiver. Group I: 40 neonates with a positive clinical sepsis score (CSS) and hematological sepsis score (HSS). Group I were subdivided into two subgroups A, B: Subgroup A: 20 Neonates with early Sepsis within the first 7 days of life. Subgroup B: 20 Neonates with late Sepsis after 7 days of life. Group II (Controls) included 20 healthy neonates with no evidence of sepsis. This study was carried out in AlQalubyia Governorate, from June 2019 to May 2020. Results: There was significant increase in HSS in sepsis group than control. Klebsilla was the common organism. there were statistically significant decrease in serum level of Apolipoprotein A1 at diagnosis among cases than control.There was no statistically significant difference between Early onset neonatal sepsis group and Late onset neonatal sepsis group regarding HSS at diagnosis. There were no statistically significant difference between Early onset neonatal sepsis group and Late onset neonatal sepsis group regarding serum level of Apolipoprotein A1 at diagnosis. Serum level of Apolipoprotein A1 at diagnosis was statistically significant lower among Early onset neonatal sepsis group than Control group. Serum level of Apolipoprotein A1 at diagnosis was statistically significant lower among late onset neonatal sepsis group than Control group. There were statistically significant positive correlation between serum level of Apolipoprotein A1 at diagnosis and Platelet count, and there was no statistically significant difference between serum level of Apolipoprotein A1 at diagnosis and other numerical data.Serum level of Apolipoprotein A1 is more accurate in the diagnosis of neonatal sepsis than HSS. Conclusion: Apo A1 appeared to be a useful marker for the early detection and diagnosis of neonatal sepsis than HSS.
\end{abstract}

Key words: Apolipoprotein A1- neonatal sepsis-Hematological score.

\section{Introduction}

Neonatal sepsis has become a global health problem due to its high morbidity and mortality [1].

Worldwide, approximately 0.6 million newborns die from sepsis each year, which accounts for $22 \%$ of neonatal deaths. This is a serious challenge for clinicians [2].

The diagnostic criterion for sepsis is blood culture, which usually takes $42-72$ hours to obtain a result and has a low sensitivity. These shortcomings often result in delayed and missed diagnoses. As neonatal sepsis is an advanced stage of non-sepsis, early diagnosis and treatment of neonatal infection is an important guarantee to prevent sepsis caused by non-sepsis. [3]

However, compared with normal newborns, there is no specific clinical manifestation or test index for non-sepsis in newborns. At present, the indicators commonly used in the clinic are white blood cell (WBC), procalcitonin (PCT) and C-reactive protein (CRP) levels, which play important roles in the diagnosis of neonatal infection. The accuracy of WBC counts in distinguishing between infectious diseases and non-infectious inflammatory disorders is very low [4].
Blood culture continues to be the main method to diagnose neonatal sepsis, but at least $48 \mathrm{~h}$ is needed for the earliest result to be obtained, and it can show no growth despite the presence of sepsis; thus, many other methods are studied to diagnose neonatal sepsis. [5].

Apolipoprotein A1 (Apo A1) is the major protein component of high-density lipoprotein (HDL) in plasma and chylomicrons secreted from the intestinal enterocyte.Apo A1 is also a cofactor for lecithin cholesterol acy1 transferase, the enzyme responsible for the formation of cholesteryl esters in plasma. Apo A1 is one of these infection markers. Apo A1 is the major protein component of HDL in plasma. The concentration of Apo A1 is decreased during an acute infection [6].

The present work aimed to study of serum level of Apolipoprotein A1 as a diagnostic marker in neonatal sepsis in Relation to Hematological score.

\section{Patients and Methods \\ 2.1. Patients}

This study is a case control study, which was done on 60 neonates who admitted to neonatal ICU (NICU) of Benha University Hospitals and Benha Teaching Hospitals of both sexes after obtaining an 
informed consent from the children's caregiver. Group I: 40 neonates with a positive clinical sepsis score (CSS) and hematological sepsis score (HSS). Group I were subdivided into two subgroups A, B: Subgroup A: 20 Neonates with early Sepsis within the first 7 days of life. Subgroup B: 20 Neonates with late Sepsis after 7 days of life. Group II (Controls) included 20 healthy neonates with no evidence of sepsis. This study was carried out in Al-Qalubyia Governorate, from June 2019 to May 2020.

The study was under the following Inclusion and exclusion criteria:-

\subsection{Inclusion criteria}

- Neonates admitted to neonatal ICU (NICU).

- Both sexes (Males and females).

- Gestational age(32- 42 week)

- Age : from $0-28$ days

\subsection{Exclusion criteria}

Any newborn who suffered from:

- Multiple congenital anomalies.

- Congenital infection like TORCH.

- Confirmed cases with inborn errors of metabolism.

- Hypoxic ischemic encephalopathy.

- Major birth trauma.

\subsection{Methods}

A standardized data sheet were utilized to record patient's history, clinical examination and investigations that were performed, as follows

\subsection{Full history taking}

The two groups were subjected to an assessment of history.

\subsection{Clinical examination}

Laboratory Investigations

- Apo A1 Sampling: Apo A1 was assessed at the time of diagnosis of sepsis by complete Sepsis work up (TLC, CRP, Blood Culture) and after 96 $\mathrm{h}$ using an enzyme-linked immunosorbent assay technique.

- Complete blood picture with a differential count at time of sepsis diagnosis and after four days. $\mathrm{CBC}$ was done for all samples using sysmex KX21N (Sysmex Corporation, New York, USA) for red blood cell (RBC) count, hemoglobin level, hematocrit value, WBC count (total and differential), and platelet count.

\subsection{Statistical analysis}

The collected data were tabulated and analyzed using SPSS version 16 software (Spss Inc, Chicago, ILL Company). Categorical data were presented as number and percentages. Chi square test $\left(\mathrm{X}^{2}\right)$, or Fisher's exact test (FET) were used to analyze categorical variables. Quantitative data were tested for normality using Kolomogrov Smirnove test assuming normality at $\mathrm{P}>0.05$. Quantitative data were expressed as mean \pm standard deviation, median and range. Student " $t$ " test was used to analyze normally distributed variables among 2 independent groups, or Man Whitney $U$ test for nonparametric ones. Spearman's correlation coefficient ( rho ) was used to assess correlation between non parametric variables. ROC curve was used to detect cutoff values with optimum sensitivity and specificity in early diagnosis and prediction of diagnosis of sepsis. The accepted level of significance in this work was stated at 0.05 (P $<0.05$ was considered significant).

Table (1) Components of hematological septic score (HSS).

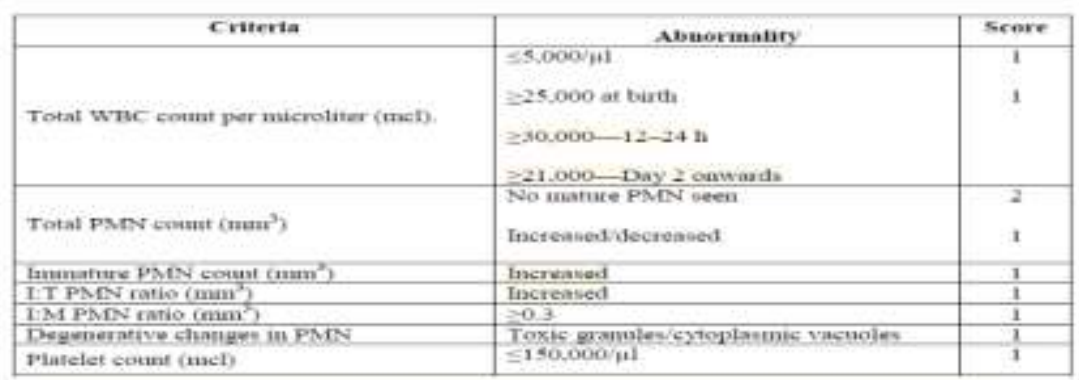

The normal values are

Total PMN count-1800-5400

Immature PMN count-600
Immature: Total PMN ratio- 0.120

Immature: Mature PMN ratio $\longrightarrow 0.3$

Table (2) Interpretation of hematological scoring system.

Interpretation is shown in Table ii. Scores are: minimum score is 0 and maximum score is 8 . Narasimha and Harendra Kumar, [7].

\begin{tabular}{ll}
\hline Score & Interpretation \\
$\leq \mathbf{2}$ & Sepsis is unlikely \\
$\mathbf{3}$ or $\mathbf{4}$ & Sepsis is possible \\
$\geq \mathbf{5}$ & Sepsis or infection is very likely
\end{tabular}

Blood cultures. Blood for culture was collected and dispensed with great care as indicated in to avoid contaminating the specimen and culture medium. 


\section{Results}

There was no statistically significant difference between cases and control regarding Age in Days and Gender Table (1).

There were statistically significant increase in Total leucocytic count, Total neutrophil count, Immature neutrophils, Immature: total neutrophil ratio (IT ratio) and Immature: mature neutrophil ratio (IM ratio) among Cases than control. There were statistically significant decrease in Platelet count among Cases than control. There were statistically significant increase in HSS at diagnosis among Cases than control Table (2).

There was statistically significant decrease in serum level of Apolipoprotein A1 at diagnosis among Cases than control Table (3).

There was no statistically significant difference between Early onset neonatal sepsis group and Late onset neonatal sepsis group regarding CBC at the time of diagnosis of sepsis and HSS at diagnosis Table (4).

There was no statistically significant difference between Early onset neonatal sepsis group and Late onset neonatal sepsis group regarding Blood Culture Table (5).

There was no statistically significant difference between Early onset neonatal sepsis group and Late onset neonatal sepsis group regarding serum level of Apolipoprotein A1 at diagnosis Table (6).

There was no statistically significant difference between Variables at diagnosis and Variables at 96 hour regarding Total leucocytic count, Platelet count, Total neutrophil count, immature neutrophils, Creactive protein (CRP) First Time, and HSS. There was statistically significant difference between Variables at diagnosis and Variables at 96 hour regarding Immature: total neutrophil ratio (IT ratio) and Immature: mature neutrophil ratio (IM ratio). Serum level of Apolipoprotein A1 at 96 hour was statistically significant higher than at diagnosis Table (7).

Table (8) show there were statistically significant positive correlation between serum level of Apolipoprotein A1 at diagnosis and Platelet count, and there was no statistically significant difference between serum level of Apolipoprotein A1 at diagnosis and other numerical data.

Table (9) show there were statistically significant positive correlation between serum level of Apolipoprotein A1 at 96 hour and Age in Days, and there was no statistically significant difference between serum level of Apolipoprotein A1 at 96 hour and other numerical data.

There were no statistically significant difference between Early onset neonatal sepsis group and Late onset neonatal sepsis group regarding serum level of Apolipoprotein A1 at diagnosis. serum level of Apolipoprotein A1 at diagnosis was statistically significant lower among Early onset neonatal sepsis group than Control group. serum level of Apolipoprotein A1 at diagnosis was statistically significant lower among late onset neonatal sepsis group than Control group Table (10).

This table shows that serum level of Apolipoprotein A1 is more accurate in the diagnosis of neonatal sepsis than HSS Table (11).

Table (3) Comparison between cases and control regarding age and sex.

\begin{tabular}{|c|c|c|c|c|c|c|}
\hline & & & $\begin{array}{c}\text { Cases } \\
(\text { No. }=40)\end{array}$ & $\begin{array}{c}\text { control } \\
\text { No. }=(20)\end{array}$ & t.test & P. value \\
\hline Age in Days & \multicolumn{2}{|c|}{ Mean \pm SD } & $8.63 \pm 5.29$ & $7.05 \pm 4.97$ & 1.110 & 0.272 \\
\hline Gender & $\begin{array}{c}\text { Female } \\
\text { Male }\end{array}$ & $\begin{array}{c}\text { No. } \\
\% \\
\text { No. } \\
\%\end{array}$ & $\begin{array}{c}19 \\
47.5 \% \\
21 \\
52.5 \%\end{array}$ & $\begin{array}{c}7 \\
35.0 \% \\
13 \\
65.0 \%\end{array}$ & $\begin{array}{c}X^{2} \\
0.848\end{array}$ & 0.357 \\
\hline
\end{tabular}

Table (4) Comparison between cases and control regarding CBC at the time of diagnosis of sepsis and HSS at diagnosis.

\begin{tabular}{|c|c|c|c|c|c|}
\hline & & cases & control & t.test & P. value \\
\hline Total leucocytic count $\left(\mathrm{x10}^{3} \mathrm{mcl}\right)$ & Mean \pm SD & $21.99 \pm 9.42$ & $11.89 \pm 3.96$ & 4.584 & 0.000 \\
\hline Platelet count $\left(\times 10 /{ }^{3} \mathrm{mcl}\right)$ & Mean \pm SD & $218.35 \pm 123.89$ & $340.60 \pm 126.94$ & -3.574 & 0.001 \\
\hline Total neutrophil count $\left(\mathrm{mm}^{3}\right)$ & Mean \pm SD & $14.47 \pm 7.37$ & $6.15 \pm 2.99$ & 4.836 & 0.000 \\
\hline Immature neutrophils $\left(\mathrm{mm}^{3}\right)$ & Mean \pm SD & $2.13 \pm 1.34$ & $0.42 \pm 0.25$ & 5.618 & 0.000 \\
\hline $\begin{array}{l}\text { Immature: total neutrophil ratio (IT } \\
\text { ratio) }\left(\mathrm{mm}^{3}\right)\end{array}$ & Mean \pm SD & $0.16 \pm 0.08$ & $0.06 \pm 0.04$ & 4.924 & 0.000 \\
\hline $\begin{array}{l}\text { Immature: mature neutrophil ratio } \\
\text { (IM ratio) }\left(\mathrm{mm}^{3}\right)\end{array}$ & Mean \pm SD & $0.20 \pm 0.14$ & $0.07 \pm 0.06$ & 4.330 & 0.000 \\
\hline HSS at diagnosis & Mean \pm SD & $5.28 \pm 1.04$ & $1.07 \pm 0.79$ & 6.49 & 0.000 \\
\hline
\end{tabular}


Table (5) Comparison between cases and control regarding serum level of Apolipoprotein A1 at diagnosis.

\begin{tabular}{|c|c|c|c|c|}
\hline & cases & control & t.test & P. value \\
\hline $\begin{array}{l}\text { serum level of } \\
\text { Apolipoprotein A1 at Mean } \pm \text { SD } \\
\text { diagnosis }(\mathrm{g} / \mathrm{dl})\end{array}$ & $5.87 \pm 2.09$ & $8.43 \pm 1.66$ & $-4.763-$ & 0.000 \\
\hline
\end{tabular}

Table (6) Comparison between Early onset neonatal sepsis group and Late onset neonatal sepsis group regarding $\mathrm{CBC}$ at the time of diagnosis of sepsis and HSS at diagnosis.

\begin{tabular}{|c|c|c|c|c|c|}
\hline & & $\begin{array}{l}\text { Early onset neonatal } \\
\text { sepsis group }\end{array}$ & $\begin{array}{l}\text { Late onset neonatal } \\
\text { sepsis group }\end{array}$ & t.test & P. value \\
\hline $\begin{array}{l}\text { Total leucocytic count }\left(x 10 /^{3}\right. \\
\text { mcl) }\end{array}$ & Mean \pm SD & $19.90 \pm 9.62$ & $24.08 \pm 8.95$ & -1.424 & .163 \\
\hline Platelet count $\left(\mathbf{x 1 0} /^{3} \mathrm{mcl}\right)$ & Mean \pm SD & $238.55 \pm 110.54$ & $198.15 \pm 135.73$ & 1.032 & .309 \\
\hline Total neutrophil count $\left(\mathrm{mm}^{3}\right)$ & Mean \pm SD & $12.81 \pm 8.06$ & $16.12 \pm 6.37$ & -1.440 & .158 \\
\hline Immature neutrophils $\left(\mathrm{mm}^{3}\right)$ & Mean \pm SD & $1.77 \pm 1.31$ & $2.47 \pm 1.30$ & -1.693 & .099 \\
\hline $\begin{array}{l}\text { Immature: total neutrophil } \\
\text { ratio (IT ratio) }\left(\mathrm{mm}^{3}\right)\end{array}$ & Mean \pm SD & $.159 \pm .086$ & $.161 \pm .080$ & -.110 & .913 \\
\hline $\begin{array}{l}\text { Immature: mature neutrophi } \\
\text { ratio (IM ratio) }\left(\mathrm{mm}^{3}\right)\end{array}$ & Mean \pm SD & $.20 \pm .13$ & $.200 \pm .134$ & .094 & .926 \\
\hline HSS at diagnosis & Mean \pm SD & $5.15 \pm .999$ & $5.10 \pm .995$ & -2.062 & .146 \\
\hline
\end{tabular}

Table (7) Comparison between Early onset neonatal sepsis group and Late onset neonatal sepsis group regarding Blood Culture.

\begin{tabular}{|c|c|c|c|c|c|c|}
\hline & & & $\begin{array}{c}\text { Early onset } \\
\text { neonatal sepsis } \\
\text { group } \\
\end{array}$ & $\begin{array}{c}\text { Late onset } \\
\text { neonatal sepsis } \\
\text { group }\end{array}$ & $\mathbf{X}^{2}$ & P. value \\
\hline \multirow[t]{14}{*}{ Blood Culture } & \multirow{4}{*}{$\begin{array}{l}\text { Coagulase Negative } \\
\text { Staph } \\
\text { E-coli }\end{array}$} & No. & 0 & 2 & \multirow[t]{14}{*}{8.848} & \multirow[t]{14}{*}{.182} \\
\hline & & $\%$ & $.0 \%$ & $10.0 \%$ & & \\
\hline & & No. & 1 & 1 & & \\
\hline & & $\%$ & $5.0 \%$ & $5.0 \%$ & & \\
\hline & \multirow[t]{2}{*}{ Gram Negtive Becilli } & No. & 2 & 0 & & \\
\hline & & $\%$ & $10.0 \%$ & $.0 \%$ & & \\
\hline & \multirow[t]{2}{*}{ Gram Positive Strept } & No. & 0 & 2 & & \\
\hline & & $\%$ & $.0 \%$ & $10.0 \%$ & & \\
\hline & \multirow{2}{*}{ klbsiella } & No. & 5 & 1 & & \\
\hline & & $\%$ & $25.0 \%$ & $5.0 \%$ & & \\
\hline & \multirow[t]{2}{*}{ No Growth } & No. & 10 & 12 & & \\
\hline & & $\%$ & $50.0 \%$ & $60.0 \%$ & & \\
\hline & \multirow[t]{2}{*}{ Pseudomones } & No. & 2 & 2 & & \\
\hline & & $\%$ & $10.0 \%$ & $10.0 \%$ & & \\
\hline
\end{tabular}

Table (8) Comparison between Early onset neonatal sepsis group and Late onset neonatal sepsis group regarding serum level of Apolipoprotein A1 at diagnosis.

\begin{tabular}{|c|c|c|c|c|c|}
\hline & & $\begin{array}{l}\text { Early onset neonatal } \\
\text { sepsis group }\end{array}$ & $\begin{array}{l}\text { Late onset neonatal } \\
\text { sepsis group }\end{array}$ & t.test & P. value \\
\hline $\begin{array}{c}\text { serum level of } \\
\text { Apolipoprotein A1 at } \\
\text { diagnosis }(\mathrm{g} / \mathrm{dl})\end{array}$ & Mean \pm SD & $6.28 \pm 2.14$ & $5.44 \pm 1.99$ & 1.282 & .208 \\
\hline
\end{tabular}

Table (9) Comparison between variables at diagnosis and variables at 96 hour.

\begin{tabular}{|c|c|c|c|c|c|}
\hline & & \multicolumn{2}{|c|}{ Variables at diagnosis Variables at 96 hour } & t.test & P. value \\
\hline $\begin{array}{c}\text { Total leucocytic count }\left(\mathbf{x 1 0} /^{3}\right. \\
\text { mcl })\end{array}$ & Mean \pm SD & $21.99 \pm 9.42$ & $19.19 \pm 10.04$ & -0.098 & 0.549 \\
\hline Platelet count $\left(\mathbf{x 1 0} /^{3} \mathrm{mcl}\right)$ & Mean \pm SD & $218.35 \pm 123.89$ & $200.43 \pm 148.01$ & 0.215 & 0.182 \\
\hline Total neutrophil count $\left(\mathrm{mm}^{3}\right)$ & Mean \pm SD & $14.47 \pm 7.37$ & $12.34 \pm 7.51$ & -0.003 & 0.987 \\
\hline
\end{tabular}




\begin{tabular}{|c|c|c|c|c|c|}
\hline Immature neutrophils $\left(\mathrm{mm}^{\mathbf{3}}\right)$ & Mean \pm SD & $2.13 \pm 1.34$ & $1.99 \pm 1.37$ & $-0.194-$ & 0.231 \\
\hline $\begin{array}{l}\text { Immature: total neutrophil } \\
\text { ratio (IT ratio) }\left(\mathrm{mm}^{3}\right)\end{array}$ & Mean \pm SD & $0.16 \pm 0.08$ & $0.16 \pm 0.06$ & 0.487 & 0.275 \\
\hline $\begin{array}{l}\text { Immature: mature neutrophil } \\
\text { ratio (IM ratio) }\left(\mathrm{mm}^{3}\right)\end{array}$ & Mean \pm SD & $0.20 \pm 0.14$ & $0.20 \pm 0.09$ & 0.407 & 0.691 \\
\hline $\begin{array}{c}\text { C-reactive protein }(\mathrm{CRP}) \mathrm{mg} / \mathrm{dl} \\
\text { HSS }\end{array}$ & $\begin{array}{l}\text { Mean } \pm \text { SD } \\
\text { Mean } \pm \text { SD }\end{array}$ & $\begin{array}{c}43.88 \pm 32.71 \\
3.28 \pm 1.037\end{array}$ & $\begin{aligned} 46.85 & \pm 46.25 \\
3.20 & \pm 1.07\end{aligned}$ & $\begin{array}{c}-0.011 \\
0.065\end{array}$ & $\begin{array}{l}0.945 \\
0.691\end{array}$ \\
\hline $\begin{array}{c}\text { serum level of Apolipoprotein } \\
\text { A1 (g/dl) } \\
\end{array}$ & Mean \pm SD & $5.87 \pm 2.09$ & $8.33 \pm 2.62$ & -0.177 & 0.001 \\
\hline
\end{tabular}

Table (10) Correlation between serum level of Apolipoprotein A1 at diagnosis and other numerical variables.

\begin{tabular}{lcc}
\hline & serum level of Apolipoprotein A1 at diagnosis (g/dl) \\
& r & 0.372 \\
\hline Age in Days & -0.145 & 0.492 \\
gestitional age & -0.112 & 0.215 \\
apgar score at $\mathbf{1}$ min & -0.201 & 0.058 \\
apgar score at 5 min & -0.302 & 0.178 \\
Birth weight measurement & -0.217 & 0.068 \\
Total leucocytic count & 0.291 & 0.002 \\
Platelet count & 0.468 & 0.457 \\
Total neutrophil count & 0.121 & 0.965 \\
Immature neutrophils & -0.007 & 0.384 \\
Immature: total neutrophil ratio (IT ratio) & -0.142 & 0.652 \\
Immature: mature neutrophil ratio (IM ratio) & -0.074 & 0.119 \\
C-reactive protein (CRP) First Time & -0.251 & 0.177 \\
HSS at diagnosis & -0.218 & \\
\hline
\end{tabular}

Table (11) Correlation between serum level of Apolipoprotein A1 at 96 hour and other numerical variables.

\begin{tabular}{lcc}
\hline & serum level of Apolipoprotein A1 at 96 hour (g/d) \\
& $\mathbf{r}$ & $\mathbf{p}$ \\
\hline Age in Days & 0.342 & 0.031 \\
gestitional age & 0.300 & 0.060 \\
apgar score at 1 min & 0.254 & 0.114 \\
apgar score at 5 min & 0.226 & 0.161 \\
Birth weight measurement & 0.242 & 0.133 \\
Total leucocytic count & -0.297 & 0.063 \\
Platelet count & 0.013 & 0.935 \\
Total neutrophil count & -0.269 & 0.093 \\
Immature neutrophils & -0.195 & 0.229 \\
Immature: total neutrophil ratio (IT ratio) & -0.024 & 0.884 \\
Immature: mature neutrophil ratio (IM ratio) & -0.023 & 0.887 \\
C-reactive protein (CRP) After Four Days & 0.100 & 0.539 \\
HSS at 96 hour & 0.181 & 0.263 \\
serum level of Apolipoprotein A1 at diagnosis & -0.177 & 0.275 \\
\hline
\end{tabular}

Table (12) Comparison between Early onset neonatal sepsis, Late onset neonatal sepsis and control regarding serum level of Apolipoprotein A1 at diagnosis.

\begin{tabular}{|c|c|c|c|c|c|c|c|}
\hline & & $\begin{array}{c}\text { Early onset } \\
\text { neonatal sepsis }\end{array}$ & $\begin{array}{c}\text { Late onset } \\
\text { neonatal sepsis }\end{array}$ & control & F.test & P. value & $\mathbf{p}$ \\
\hline $\begin{array}{l}\text { serum level of } \\
\text { Apolipoprotein A1 } \\
\text { at diagnosis (g/dl) }\end{array}$ & Mean \pm SD & $6.2 \pm 2.1$ & $5.4 \pm 1.9$ & $\begin{array}{c}8.43 \pm \\
1.66\end{array}$ & 12.445 & .000 & $\begin{array}{l}\mathrm{P} 1=0.177 \\
\mathrm{P} 2=0.001 \\
\mathrm{P} 3=0.000\end{array}$ \\
\hline
\end{tabular}

P1-- $\square$ between Early onset neonatal sepsis group and Late onset neonatal sepsis group

P2- $\square$ between Early onset neonatal sepsis group and Control group

P3- $\square$ between Late onset neonatal sepsis group and Control group 
Table (13) Performance of serum level of Apolipoprotein A1 and HSS in diagnosis of cases.

\begin{tabular}{lcccccc}
\hline Marker cutoff & AUC & Sens\% & Spec\% & PPV\% & NPV\% & P \\
\hline serum level of Apolipoprotein A1< 3.8 (g/dl) & 0.97 & $84.4 \%$ & $89.3 \%$ & $90 \%$ & $83.3 \%$ & 0.00 \\
HSS $\geq \mathbf{2}$ & 0.74 & $69.7 \%$ & $74.1 \%$ & $76.7 \%$ & $66.7 \%$ & 0.00 \\
\hline
\end{tabular}

\section{Discussion}

Regarding $\mathrm{CBC}$, our results revealed that, there were significant increase in WBCs among patients than controls. This was in agreement with Ahmed and Mahmoud, [8] who found that, there was significant increase of WBCs in the septic neonates group when compared with control group. This finding was comparable with that of the studies by Srinivasan and Harris, [9]. They concluded that TLC is useful to estimate the probability of sepsis. However, Laurent et al., [10] found that the total leukocytic count had little value in discriminating infection in neonates.

In the present work, the mean count of platelets in the sepsis group was significantly lowered compared with the controls. This was in agreement with Shalaby et al., [11] who found platelets was statistically significant decrease in sepsis group than the control group.

In this study there was significant increase in HSS in sepsis group than control. This was in agreement with El-Gendy et al., [6] who reported that HSS was significantly higher in septic neonates than those with no sepsis

In this study, regarding blood culture among cases group, Klebsilla was the common organism $(15 \%)$, psoudomonas (10\%), E.coli (5\%).

Also El-Mashad et al., [12] who found that, $23.3 \%$ had negative blood cultures and $76.6 \%$ of the case group (23 patients) had positive blood cultures; $36.7 \%$ of these were positive for Klebsiella spp., $16.7 \%$ were positive for Staphylococcus aureus, $13.3 \%$ were positive for Escherichia coli, $6.7 \%$ were positive for b-hemolytic streptococci, and $3.3 \%$ were positive for Candida albicans

In this study, there were statistically significant decrease in serum level of Apolipoprotein A1 at diagnosis among cases than control.

This was in agreement with El-Gendy et al., [6] who reported that, there was a statistically significant decrease in the mean Apo A1 level in patients at the time of diagnosis compared with the control group, ( $\mathrm{P}$ $<0.001)$. This was in agreement with Giunti et al., [13] who found significant lower Apo-A1 concentrations were documented in sepsis compared to healthy ones.

This was in agreement with Zou et al., [14] who found in patients with sepsis, apolipoprotein A 1 (apoA 1) were significantly decreased in this group compared to control group.

In our study, Group I were subdivided into two subgroups A , B: Subgroup A: 20 Neonates with early Sepsis within the first 7 days of life. Subgroup B: 20 Neonates with late Sepsis after 7 days of life.

Shehab El-Din et al., [15] found that, 344 neonates were enrolled in the study in which 152
$(44.2 \%)$ were classified as early onset sepsis EOS and $192(55.8 \%)$ as late onset sepsis LOS. Among the studied neonates, LOS $(55.8 \%)$ was more common than EOS (44.2\%).

In this study, There was no statistically significant difference between Early onset neonatal sepsis group and Late onset neonatal sepsis group regarding $\mathrm{CBC}$.

This was in agreement with Ogundare et al., [16] who found that There was no statistically significant difference between EOS and LOS regarding CBC.

This study showed that, there was no statistically significant difference between Early onset neonatal sepsis group and Late onset neonatal sepsis group regarding HSS at diagnosis. This was in agreement with El-Gendy et al., [6] who found that there is no significant statistical difference between early-onset and late-onset sepsis regarding HSS.

This study showed that, there were no statistically significant difference between Early onset neonatal sepsis group and Late onset neonatal sepsis group regarding serum level of Apolipoprotein A1 at diagnosis. Serum level of Apolipoprotein A1 at diagnosis was statistically significant lower among Early onset neonatal sepsis group than Control group. Serum level of Apolipoprotein A1 at diagnosis was statistically significant lower among late onset neonatal sepsis group than Control group. This study showed that, there were statistically significant positive correlation between serum level of Apolipoprotein A1 at diagnosis and Platelet count, and there was no statistically significant difference between serum level of Apolipoprotein A1 at diagnosis and other numerical data.

El-Gendy et al., [6] reported that, there was no significant correlation between the level of Apo A1 and gestational age, weight, hemoglobin, hematocrit, total leukocytic count, platelets, alanine aminotransferase, aspartate aminotransferase, urea, and creatinine of neonates, but there was a positive significant correlation between Apo A1 and the Apgar score at the first minute and the fifth minute at diagnosis of neonatal sepsis and after $96 \mathrm{~h}$. Also, there was a significant negative correlation between Apo A1 and immature to total leukocyte ratio, immature to mature leukocyte ratio, CSS, HSS, and CRP at diagnosis of neonatal sepsis and after $96 \mathrm{~h}$.

This study showed that, serum level of Apolipoprotein A1 is more accurate in the diagnosis of neonatal sepsis than HSS. This was in agreement with El-Gendy et al., [6] who reported that, Apo A1 considered a perfect marker to diagnose sepsis with a diagnostic sensitivity of $100 \%$, a specificity of $100 \%$, and an accuracy of $100 \%$ and more accurate in than HSS. 


\section{Conclusion}

Apo A1 appeared to be a useful marker for the early detection and diagnosis of neonatal sepsis than HSS. The Apo A1 lipoprotein level is decreased in newborns with neonatal sepsis compared with controls

\section{References}

[1] MS.El Shimi, NM.Abou Shady, GM.Hamed. Significance of neutrophilic CD64 as an early marker for detection of neonatal sepsis and prediction of disease outcome. J. Matern. Fetal. Neonatal. Med.vol. 30,pp.1709-1714,2017.

[2] I.Nour, HE.Eldegla, N.Nasef. Risk factors and clinical outcomes for carbapenem-resistant Gram-negative late-onset sepsis in a neonatal intensive care unit. J Hosp Infect.vol. 97(1),pp.52$58,2017$.

[3] R.Pradhan, P.Jain, A.Paria. Ratio of neutrophilic CD64 and monocytic HLA-DR: A novel parameter in diagnosis and prognostication of neonatal sepsis. Cytometry B Clin Cytom.vol. 90(3),pp.295-302, 2016.

[4] J.ten Oever, MG.Netea, BJ.Kullberg. Utility of immune response-derived biomarkers in the differential diagnosis of inflammatory disorders. J. Infect.vol. 72,pp.1-18,2016.

[5] PY.Iroh Tam, and C.Bendel. Diagnostics for neonatal sepsis: current approaches and future directions. Pediatr Res.vol. 82,pp. 574-583,2017.

[6] FM.El-Gendy, R.DM.El-Lahony, DA.Midan. Diagnostic value of apolipoprotein A1 in neonatal sepsis. Menoufia Med J.vol.31,pp.1011-7,2018.

[7] A.Narasimha, M.L.Harendra Kumar. Significance of Hematological Scoring System (HSS) in Early Diagnosis of Neonatal Sepsis. Indian journal of hematology \& blood transfusion : an official journal of Indian Society of Hematology and Blood Transfusion.vol. 27(1), pp.14-17,2011.

[8] A.S.Ahmed, M.Mahmoud Salah. Evaluation of cord blood and serum Hepcidin levels as biomarkers for neonatal sepsis Al -. Azhar Assiut Medical Journal (AAMJ).vol. 13(3),pp.1-16, 2015.

[9] L.Srinivasan, MC.Harris. New technologies for the rapid diagnosis of neonatal sepsis. Curr Opin Pediatr.vol.24(2),pp.165-71,2012.

[10] R.Laurent, S.Caroline, K.Eric. A composite score combining procalcitonin, C-reactive protein and temperature has a high positive predictive value for the diagnosis of intensive care- acquired infections. BMC Infectious Diseases.vol.13,pp.159,2013.

[11] M.M.Shalaby, A.A.Sobeih, W.E.Abdulghany. Mean platelet volume and serum uric acid in neonatal sepsis: A case-control study. Annals of Medicine and Surgery.vol. 20, pp.97-102,2017.
[12] GM.El-Mashad, HM.El-Sayed, OH.Salem. Serum leptin level as a marker of neonatal sepsis. Menoufia Med J.vol.29,pp.252-8,2016.

[13] M.Giunti, G.Grossi, R.Troía. Evaluation of Serum Apolipoprotein A1 in Canine Sepsis. Frontiers in Veterinary Science.vol. 7,pp.7-9, 2020.

[14] G.Zou, J.He, B.Ren. The delta high-density lipoprotein cholesterol ratio: a novel parameter for gram-negative sepsis. SpringerPlus.vol.5(1),pp. 1044,2016.

[15] E.M.R.Shehab El-Din, M.M.A.El-Sokkary, M.R.Bassiouny, R.Hassan. Epidemiology of Neonatal Sepsis and Implicated Pathogens: A Study from Egypt. BioMed Research International.vol. 1,pp.11,2015.

[16] E.Ogundare, A.Akintayo, T.Aladekomo. Presentation and outcomes of early and late onset neonatal sepsis in a Nigerian Hospital. African health sciences.vol.19(3),pp.2390-2399,2019. 